\title{
Büllöz pemfigoidli hastalarda 3 yillık gözlem: 29 olgu
}

\author{
Three-year observation of the patients with bullous pemphigoid: 29 cases
}

\section{Özlem Ekiz, Bilge Bülbül Șen, Emine Nur Rifaioğlu, Tuğba Șen, Esin Atik*, Asena Çiğdem Doğramacı}

Mustafa Kemal Üniversitesi Tıp Fakültesi, Dermatoloji Anabilim Dalı, *Patoloji Anabilim Dalı, Hatay, Türkiye

\section{Özet}

Amaç: Büllöz pemfigoid (BP) kronik, otoimmun subepidemal büllöz bir hastalıktır. Çalışmamızdaki amaç, son 3 yılda kliniğimizde BP tanısı konulan olguların klinik ve epidemiyolojik özelliklerini belirlemek ve sonuçlarımızı ülkemizdeki ve dünyanın diğer yerlerindeki sonuçlarla karşılaştırmaktır.

Gereç ve Yöntem: Ocak 2009 ve Ocak 2013 tarihleri arasında Dermatoloji polikliniğimize başvuran, klinik ve histopatolojik olarak BP tanısı alan hastaların dosyaları retrospektif olarak değerlendirildi. Hastaların yaş, cinsiyet, oral mukoza tutulumu, kaşıntının varlığı, hastalık süresi, tetikleyici faktör bulunup bulunmaması, deri lezyonlarının özellikleri, biyopsi örneklerinin direk immünofloresan (DIF) inceleme sonuçları, tedavide kullanılan ilaçlar, nüks ve eksitus oranları ve saptanabilen ölüm nedenleri gibi klinik ve demografik verileri kaydedildi.

Bulgular: Çalışmaya alınan 29 hastanın \%48,3'ü kadın, \%51,7'i erkekti. Yaş ortalamaları 70,17 yıl iken, ortalama hastalık suresi 15,41 aydı. Oral mukoza tutulumu beş, kaşıntı 24 olguda saptandı. Tetikleyici faktör olarak üç olguda ilaç, bir olguda da malinite belirlendi. DIF inceleme sonuçlarında dermoepidermal bileşkede lineer IgG ve C3 depolanması 12 olguda, C3 depolanması 10 olguda mevcuttu. Hastalara başlangıç tedavisi olarak 11 hastaya topikal kortikosteroid, altı hastaya tetrasiklin and nikotinamid kom-binasyonu, 10 hastaya sistemik kortikosteroid tedavisi verildi. Yedi hastada verilen ilk tedaviden sonra bir yil içinde nüks meydana geldi. Hastane içi mortalite iki hastada görüldü.

Sonuç: Çalışmamızda son 3 yılda kliniğimizde BP tanısı konulan hastalarının klinik ve epidemiyolojik verileri sunulmuştur. illimiz farklı etnik gruplardan oluşan heterojen bir popülasyon olduğu için, çalışmamızın ülkemizdeki BP ile ilgili epidemiyolojik verilerin oluşturulmasında katkıda bulunacağına inanıyoruz. Ancak bu konuda yapılmış prospektif, daha uzun süreli ve çok merkezli çalışmalara ihtiyaç duyulmaktadır. (Türkderm 2013; 47: 205-8)

Anahtar Kelimeler: Büllöz pemfigoid, epidemiyoloji, retrospektif çalışma

\section{Summary}

Background and Design: Bullous pemphigoid (BP) is a chronic, autoimmune, subepidermal blistering skin disease. The aim of this study was to determine the clinico-epidemiological characteristics of patients diagnosed with BP in our clinic and to compare the results with those in other studies in our country and in the world.

Materials and Methods: We retrospectively evaluated medical records of patients with BP diagnosed by clinical and histopathological examinations in our clinic from January 2009 to January 2013. We evaluated data on demographic characteristics, age, sex, existence of oral mucosal lesions, association of pruritus, duration of the disease, presence of triggering factors, features of the skin lesions, results of direct immunofluorescence (DIF) investigations, drug intake, recurrence and mortality rates and causes of de-tected mortality in all patients.

Results: Of the 29 patients included in the study, $\% 48.3$ were female, $\% 51.7$ were male. The average age was 70.17 years and the mean duration of the disease was 15.41 months. We detected oral mucosal involvement in five cases, and pruritus in 24 patients. Drugs use in three cases and malinity in one patient were considered be be an trigger factor. The results of DIF investigation revealed linear IgG and C3 deposition at the dermoepidermal junction in 12 cases and C3 deposition in 10 cases. The initial treatment was topical corticosteroid in 11 , tetracycline and nicotinamide combination in six and systemic corticosteroid in 10 individuals. After initial therapy, recurrence appeared in 7 patients within one year. Mortality during hospitalization was observed in 2 cases.

Conclusion: We presented the clinical and epidemiological features of patients diagnosed with BP in our clinics in the past three years. Considering the presence of different ethnic groups and population heterogenity in our city, we believe that our investigation will contribute to our understanding of the epidemiology of BP in our country. Nevertheless, prospective, long-term and large population-based multicenter studies are needed. (Turkderm 2013; 47: 205-8)

Key Words: Bullous pemfigoid, epidemiology, retrospective study

Yazışma Adresi/Address for Correspondence: Dr. Özlem Ekiz, Mustafa Kemal Üniversitesi Tıp Fakültesi, Dermatoloji Anabilim Dalı, Hatay, Türkiye Tel.: +90 3262293395 E-posta: drozlemekiz@yahoo.com.tr Geliş Tarihi/Received: 21.01.2013 Kabul Tarihi/Accepted: XX 


\section{Giriş}

Büllöz pemfigoid (BP), Batı Avrupa'da en sık görülen otoimmun büllöz hastalıktır. Sıklıkla 60 yaş ve üzeri kişilerde, eritemli zemin üzerinde, kaşıntılı, gergin büllerle karakterizedir. İnsidansı yaşla birlikte artmakta ve farklı etnik popülasyonlarda değişmektedir 1-3. Dünyanın farklı bölgelerinden BP ile ilgili çok sayıda klinikoepidemiyolojik çalışma bildirilmiştir4-14. Ülkemizden de BP ile ilgili 3 farklı epidemiyolojik çalışma bulunmaktadır15-17.

Çalışmamızın amacı, son 3 yılda kliniğimizde BP tanısı konulan olguların kliniko epidemiyolojik özelliklerini belirlemek ve sonuçlarımızı ülkemizdeki ve dünyanın diğer yerlerindeki sonuçlarla karşılaştırmaktır.

\section{Yöntem ve Gereçler}

Çalışmamızda Ocak 2009-Ocak 2013 tarihleri arasında Dermatoloji polikliniğimize başvuran, klinik ve histopatolojik olarak BP tanısı alan hastaların dosyaları retrospektif olarak değerlendirildi. Yaş, cinsiyet, deri lezyonlarının yaygınlığı (\%20'den az tutulum lokal hastalık olarak kabul edildi) ve özellikleri, oral mukoza tutulumu, kaşıntının varlığı, hastalık süresi, tetikleyici faktör varlığı (ilaçlar, maliniteler, vs), biyopsi sonuçları, tedavide kullanılan ilaçlar, nüks ve mortalite oranları ve saptanabilen ölüm nedenleri kaydedildi. Veriler IBM uyumlu bilgisayarda SPSS 19'da (Statistical Programmes for Social Sciences) değerlendirildi.

\section{Bulgular}

Çalışmaya alınan toplam 29 hastanın 14'ü $(\% 48,3)$ kadın, 15'i $(\% 51,7)$ erkekti. Kadın/erkek oranı 0,93 olarak saptandı. Hastaların yaşları 34-

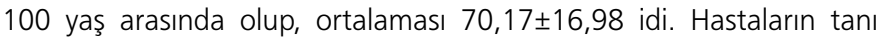
anındaki yaş ve cinsiyet dağılımları Şekil 1'de gösterilmiştir. Hastalık

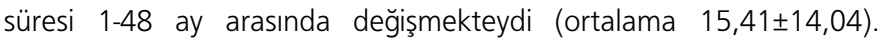
Hastaların demografik özellikleri ise Tablo 1'de gösterilmiştir. Hastaların 4'ünde $(\% 13,8)$ lokalize BP mevcuttu. Oral mukoza tutulumu beş $(\% 17,24)$ hastada saptanırken, kaşıntı $24(\% 82,8)$ hastada mevcuttu. Tetikleyici faktör dört $(\% 13,8)$ olguda saptandı. Bunlardan üç olguda ilaç (bir olgu siprofloksasin, iki olgu da çoklu ilaç kullanımı), bir olguda da hematolojik malinite tetikleyici faktör olarak belirlendi. Deri lezyonlarının özelliklerine baktığımızda her iki cinste de en sık lezyonun ürtikeryal plak ve bülloz lezyonlar olduğu görüldü. Yirmi iki olguya klinik, histopatolojik ve DIF bulgularına göre, 7 olguya da klinik ve histopatolojik bulgulara göre BP tanısı konulduğu görüldü. DIF inceleme sonuçlarında 12 olguda $(\% 54,54)$ dermoepidermal bileşkede lineer IgG ve C3 depolanması, 10 olguda $(\% 45,45)$ C3 depolanması mevcuttu. Başlangıç tedavisi olarak 11 hastaya $(\% 37,9)$ topikal kortikosteroid, 6 hastaya $(\% 20,7)$ tetrasiklin ve nikotinamid kombinasyonu, 10 hastaya $(\% 34,5)$ sistemik kortikosteroid tedavisi verildiği kaydedildi. Yedi $(\% 24,13)$ hastada verilen ilk tedaviden sonra bir yıl içinde nüks meydana geldi. Bunların ikisinde $(\% 28,57)$ sadece topikal kortikosteroid kullanımı, dördünde $(\% 57,14)$ tetrasiklin ve nikotinamid kombinasyonu ve birinde $(\% 14,28)$ de sadece sistemik kortikosteroid kullanımı mevcuttu. Nüksten sonra verilen tedaviler incelendiğinde ise bir hastaya tetrasiklin ve nikotinamid, bir hastaya sistemik kortikosteroid ve azatiyopürin ve beş hastaya da sadece sistemik kortikosteroid başlandığı belirlendi. Hastane içi mortalite iki hastada $(\% 6,9)$ görüldü. Hastalardan birincisi iki aydır sistemik metilprednisolon tedavisi (24 mg) alıyordu. Tedavi sırasında gelişen nekrotizan fasiit nedeni ile izlendiği dönemde, akut böbrek yetmezliğ gelişen hastada yoğun bakımda eksitus gelişti. İleri yaştaki ikinci hasta ise üç haftalık metilprednisolon tedavisi (48 mg) alırken yaygın hastalık, genel durum bozukluğu ve nedeni tam olarak açıklanamayan kardiyopulmoner kollaps nedeniyle eksitus oldu.

\section{Tartışma}

BP, Batı Avrupa'da en sık görülen otoimmun büllöz bir hastalıktır. Her yaşta görülebilmekle beraber, 60 yaş ve üzeri kişilerde daha sık rastlanmaktadır. BP için yıllık insidanslar Avrupa ülkerinden 2,542,8/milyon8-12,18, Asya ülkelerinden de 2,6-23,6/milyon olarak

\section{Tablo 1. Hastaların karakteristik özellikleri}

\begin{tabular}{|c|c|}
\hline Karakteristik Özellikler & \\
\hline \multicolumn{2}{|l|}{ Cinsiyet } \\
\hline Kadın & $14(\% 48,3)$ \\
\hline Erkek & $15(\% 51,7)$ \\
\hline$K / E$ & 0,93 \\
\hline \multicolumn{2}{|l|}{ Yaş } \\
\hline Aralık & $34-100$ \\
\hline Ortalama $\pm S D$ & $70,17 \pm 16,98$ \\
\hline \multicolumn{2}{|l|}{ Hastalık Süresi (ay) } \\
\hline Aralık & $1-48$ \\
\hline Ortalama $\pm S D$ & $15,41 \pm 14,04$ \\
\hline Mukozal Tutulum Varlığı & $5(\% 17,24)$ \\
\hline Kaşıntı Varlığı & $24(\% 82,8)$ \\
\hline \multicolumn{2}{|l|}{ Tetikleyici Faktör Varlığı } \\
\hline ìlaç & $3(\% 10,34)$ \\
\hline Malinite & $1(\% 3,44)$ \\
\hline \multicolumn{2}{|l|}{ Ek Hastalık } \\
\hline & $\begin{array}{l}\text { HT } 10(\% 34,48), \text { DM 5(\%17,24), } \\
\text { İH 1(\%3,44), KAH 1(\%3,44), } \\
\text { BPH 1(\%3,44),Vitiligo 1(\%3,44), } \\
\text { Kronik Karaciğer Hastalığı 1(\%3,44), }\end{array}$ \\
\hline \multicolumn{2}{|l|}{ DIF Bulguları } \\
\hline IgG ve C3 depolanması & $12(\% 41,37)$ \\
\hline C3 depolanması & $10(\% 34,48)$ \\
\hline Yok & $7(\% 24,1)$ \\
\hline \multicolumn{2}{|l|}{ Başlangıç tedavisinde } \\
\hline \multicolumn{2}{|l|}{ kullanılan ilaçlar } \\
\hline Topikal kortikosteroid & $11(\% 37,9)$ \\
\hline Tetrasiklin+nikotinamid & $6(\% 20,7)$ \\
\hline Sistemik kortikosteroid & $10(\% 34,5)$ \\
\hline $\begin{array}{l}\text { Topikal kortikosteroid+ } \\
\text { tetrasiklin }\end{array}$ & $1(\% 3,4)$ \\
\hline $\begin{array}{l}\text { Sistemik kortikosteroid+ } \\
\text { azatiyoprin }\end{array}$ & $1(\% 3,4)$ \\
\hline Nüks & $7(\% 24,13)$ \\
\hline Hastane içi mortalite & $2(\% 6,9)$ \\
\hline
\end{tabular}

HT, Hipertansiyon; DM, Diyabetes mellitus; IBH, Inflamatuvar barsak hastalığı;

$\mathrm{KAH}$, Koroner arter hastalığı; BPH, Benign prostat hipertrofisi 


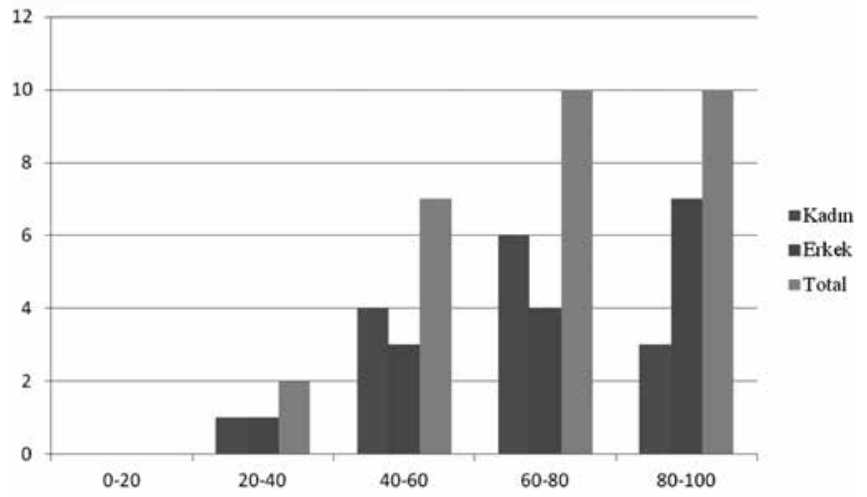

Resim 1. Hastaların yaş ve cinsiyete göre dağılımları

bildirilmektedir4-7,13,14. Ülkemizden yapılan üç farklı çalışmada yıllık insidanslar3,1-16,5 arasında değişmektedir15-17. Hem ülkemizde hem de dünyanın diğer yerlerinde son yıllarda yapılan çalışmalarda BP insidansının giderek arttığı görülmektedir. Bizim çalışmamızda da kliniğimizde son 3 yılda 29 olgunun BP tanısı aldığı saptanmıştır. Bu da yılda 9,6 olguya denk düşmektedir. Ayrıca olgularımızın çoğunun son bir yılda saptandığı görülmüştür. Asyadan yapılan bazı çalışmalarda kadın cinsiyet daha baskın gözlenirken6,13, Avrupadan yapılan çalışmalarda genellikle ya eşit cinsiyet dağılımı ya da hafif bir erkek hakimiyeti bildirilmiştir8-12,18. Ülkemizden yapılan diğer çalışmalarda da hafif bir kadın hakimiyeti bulunmaktadır15-17. Çalışmamızda ise kadın erkek oranı yaklaşık olarak birbirine eşit bulunmuştur. Tanı anındaki ortalama yaş değerlendirildiğinde $70,17 \pm 16,98$ yıl olarak saptadı, bu değer literatürle uyumlu bulundu $(73,7-82,4 \pm 7,4$ yıl)6,8,9,19,20. Literatürlerde yaşlı popülasyonda erkek cinsiyet hakimiyeti bulunmuştur2,11,12. Bizim çalışmamızda da benzer şekilde 60-80 yaş aralığında daha çok kadın hakimiyeti bulunurken, 80-100 yaş aralığında ise daha çok erkek hakimiyeti gözlenmiştir. Hastalık süresi ve mukozal tutulum açısından sonuçlarımız literatürlere benzer şekildeydi7,9,16,21. Hastalarda \%82,8 oranında kaşıntı şikayeti mevcuttu, bu oran Akay ve arkadaşlarının yaptıkları çalışmadan $(\% 77,4)$ biraz daha yüksekti16. Birçok ilacın BP'yi tetikleyebildiği bilinmektedir. Bunlardan başlıcaları diüretikler, analjezikler, D-penisilamin, antibiyotikler ve kaptoprildir. İsviçre'de yapılan bir çalışmada hastaların tanı anında \%30 oranında nöroleptik ve \%34 oranında diüretik kullandıkları ve \%11 oranında da hastalarda eş zamanlı bir malinitenin olduğu belirtilmiştir ${ }^{11}$. Birçok çalışmada da malinite ile BP arasındaki ilişki olduğu gösterilmiştir23. İsveç'ten yapılan geniş çaplı bir çalışmada ise malinite ile BP arasında herhangi bir ilişki saptanmamıştır. Ayrıca BP ile malinitelerin birlikte görülmesinin tesadüfi olduğunu ve her iki hastalığında yaşlı popülasyonu etkilemesine bağlı olduğunu da belirtmişlerdir. Ülkemizden Akay ve arkadaşlarının çalışmasında ise olguların hiçbirisinde tetikleyici faktör olarak ilaç veya eş zamanlı malinite saptanmamıştır ${ }^{16}$. Çalışmamızda ise tetikleyici faktör olarak üç olguda $(\% 10,34)$ ilaç ve bir olguda da $(\% 3,44)$ eş zamanlı hematolojik maliniteye rastlanıldı. BP'ye, diğer otoimmun hastalıkların ve çoğunlukla ileri yaşların hastalığı olması sebebi ile de kardiyovasküler ve nörolojik hastalıkların daha sık eşlik etmesi beklenmektedir. Bizim çalışmamızda da BP'ye, otoimmun hastalıklardan olan DM $(\% 17,24)$, vitiligo $(\% 3,4)$ ve İB $(\% 3,4)$ ve yaşlılarda daha sık görülen $\mathrm{KAH}(\% 3,4)$ ve $\mathrm{BPH}(\% 3,4)$ eşlik etmekteydi. BP'nin mortalite oranı pemfigus vulgarise göre çok daha düşüktür. Mortaliteye katkıda bulunan faktörler, BP'nin daha çok yaşlı kişilerde görülmesi, kadın cinsiyet, genel durum bozukluğu, eşlik eden sistemik hastalıkların varlığı, tedavide yüksek doz kortikosteroidlerin verilmesi ile ilişki olarak bilinmektedir21,24,26. Avrupadan, BP'nin bir yıllık mortalite oranlarına yönelik çok çeşitli yayınlar mevcuttur. Bu çalışmalarda mortalite oranı \%10,8-41 olarak belirlenmiştir20,21,24,25. Ülkemizden Akay ve arkadaşlarının yaptıkları çalışmada ise mortalite oranı \%19,3 olarak hesaplanmıştır ${ }^{16}$. Bizim çalışmamızda ise mortalite oranı diğer yapılan çalışmalara oranla belirgin olarak düşük bulunmuştur $(\% 6,9)$. Bunun nedenini hastalarımıza ilk seçenek olarak topikal kortikosteroid ve tetrasiklin ve nikotinamid kombinasyon tedavisinin başlanması, sistemik kortikosteroid ve adjuvan tedavilerin ise genellikle ikinci seçenek olarak verilmesi, hastalarımızı sıklıkla ayaktan takip etmemiz, hastanede yatış sürelerini kısa tutmamız ve hastalıklarınında daha az şiddette olmasına bağlamaktayız. Bernard ve arkadaşlarının 2009 yılında yaptıkları çalışmada düşük doz topikal veya sistemik kortikosteroid tedavisi ile remisyonda olan 114 BP hastasının bir yıl içinde 45'inde $(\% 39,8)$ nüks olduğu belirlenmiştir. Ayrıca nüks olan hastaların düşük doz kortikosteroid tedavisine iyi yanıt verdiklerini de belirtmişlerdir27. Akay ve arkadaşlarının çalışmasında ise 31 olgunun 11'inde (\%35) nüks gözlenmiştir. Nüks genellikle orta doz sitemik kortikosteroid kullanan hastalarda meydana gelmiş ve ilk atak kadar şiddetli olmuştur. Nüks sonrası tedavide yine sistemik kortikosteroidler ve adjuvan ajan olarak azatiyopürin eklenmiştir ${ }^{16}$. Çalışmamızda başlangıç tedavisi olarak \%62 oranında topikal kortikosteroid ve tetrasiklin+nikotinamid kombinasyonu başlanmıştır. Başlangıç tedavisinden sonra nüks oranı $\% 24,3$ olarak belirlenmiştir. Nüks olan olguların \%28,57'sinde sadece topikal kortikosteroid kullanımı, \%57, 14'ünde tetrasiklin ve nikotinamid kombinasyonu ve \%14,28'inde de sadece sistemik kortikosteroid kullanımı bulunmaktaydı. Nüks sonrası hastalık şiddeti ya aynı veya daha şiddetli olmuştur. Nüks sonrası tedavilere baktığımızda ise $\% 71,4$ oranında sistemik kortikosteroid başlanırken, \%14,3 oranında sistemik kortikosteroid ve azatiyopürin kombinasyonu başlanmıştır.

Sonuç olarak çalışmamızda kliniğimizde üç yıl gibi kısa bir sürede 29 hastaya BP tanısı konulduğu ve hastaların büyük çoğunluğunun son bir yılda tanı aldığı dikkati çekmiştir. Illimizin farklı etnik gruplardan oluşan heterojen bir popülasyona sahip olması nedeniyle, çalışmamızın ülkemizdeki BP ile ilgili epidemiyolojik verilerin oluşturulmasında katkıda bulunacağına inanıyoruz. Ancak ilimizde yapılacak prospektif, daha uzun süreli ve çok merkezli çalışmalara intiyaç duyulmaktadır.

\section{Kaynaklar}

1. Wojnarowska F, Venning VA, Burge SM: Immunobullous diseases. Rook's Textbook of Dermatology. Ed. Burns T, Breathnach S, Cox N, Griffiths C. 7'nci baskı. Oxford, Blackwell Science 2004;41:1-41.

2. Jung M, Kipper W, Messer G, et al: Increased risk of bullous pemphigoid in male and very old patients: a population based populationbased study on incidence. J Am Acad Dermatol 1999;41:266-8.

3. Kirtschig G, Wojnarowska F: Autoimmune blistering diseases: an up-date of diagnostic methods and investigations. Clin Exp Dermatol 1994;19:97-112.

4. Adam BA: Bullous diseases in Malaysia: epidemiology and natural history. Int J Dermatol 1992;31:42-5.

5. Triki Ben Ammar S, Mokhtar I, Fazaa B, Kharfi M, Kamoun MR: Profile of bullous pemphigoid. A report of 47 cases. Tunis Med 2000;78:584-8.

6. Wong SN, Chua SH: Spectrum of subepidermal immunobullous disorders seen at the National Skin Centre, Singapore: a 2-year review. Br J Dermatol 2002;147:476-80.

7. Chang YT, Liu HN, Wong CK: Bullous pemphigoid a report of 86 cases from Taiwan. Clin Exp Dermatol 1996;21:20-2. 
8. Zillikens D, Wever S, Hashimoto T, Brocker EB: Incidence of autoimmune subepidermal blistering dermatoses in a region of central Germany. Arch Dermatol 1995;131:957-8.

9. Bernard P, Vaillant L, Labeille B, et al: Incidence and distribution of subepidermal autoimmune bullous skin diseases in three French regions. Arch Dermatol 1995:131:48-52

10. Cozzani E, Parodi A, Reboria A et al: Bullous pemphigoid in Liguria: a 2-year survey. J Eur Acad Dermatol Venereol 2001;15:317-19.

11. Marazza G, Pham HC, Scharer L, et al: Incidence of bullous pemphigoid and pemphigus in Switzerland: a 2-year prospective study. Br J Dermatol 2009;161:861-8.

12. Bertram F, Brocker EB, Zillikens D, Schmidt E: Prospective analysis of the incidence of autoimmune bullous disorders in Lower Franconia, Germany. Dtsch Dermatol Ges 2009;7:434-40.

13. Nanda A, Dvorak R, Al-Saeed K, Al-Sabah H, Alsaleh QA: Spectrum of autoimmune bullous diseases in Kuwait. Int J Dermatol 2004;43:876-81.

14. Waisbourd-Zinman $O$, Ben-Amitai $D$, Cohen $A D$, et al: Bullous pemphigoid in infancy: Clinical and epidemiologic characteristics. J Am Acad Dermatol 2008; $58: 41-8$

15. Uzun S, Durdu M, Akman A, et al: Pemphigus in the Mediterranean region of Turkey: a study of 148 cases. Int J Dermatol 2006;45:523-8.

16. Akay B.N, Bodamyalı P, Şanlı H, Akyol A: Bülloz Pemfigoidli Hastalarda 10 Yıllık Gözlem. Türkderm-Deri Hastalıkları ve Frengi Arşivi Dergisi 2010;44:61 4.

17. Lebe B, Niflioğlu GG, Seyrek S, Ellidokuz H: Otoimmün Vezikülobüllöz Dermatitlerin Klinik ve Histopatolojik/Direkt Immünfloresan Tanı Değerlendirmesi: Direkt Immünflöresansın Faydası 2012;28:11-6.
18. Langan SM, Smeeth L, Hubbard R, Fleming KM, Smith CJ, West J: Bullous pemphigoid and pemphigus vulgaris-incidence and mortality in the UK: population based cohort study. BMJ 2008;337:180

19. Korman NJ: Bullous pemphigoid. the latest in diagnosis, prognosis, and therapy. Arch Dermatol 1998;134:1137-41.

20. Colbert RL, Allen DM, Eastwood D, Fairley JA: Mortality rate of bullous pemphigoid in a US medical center. J Invest Dermatol 2004;122:1091-5.

21. Rzany $B$, Partscht $K$, Jung $M$, et al: Risk factors for lethal outcome in patients with bullous pemphigoid. Arch Dermatol 2002;138:903-8.

22. Di Zenzo G, Marazza G, Borradori L: Bullous pemphigoid: physiopathology, clinical features and management. Adv Dermatol 2007;23:257-88.

23. Venning VA, Wojnarowska F: The association of bullous pemphigoid and malinant disease: a case control study. Br J Dermatol 1990;123:439-45.

24. Roujeou J-C, Lok C, Bastuji-Garin S et al: High risk of death in elderly patients with extensive bullous pemphigoid. Arch Dermatol 1998;134:465-9.

25. Bernard P, Bedane C, Bonnetblanc JM: Anti-BP180 autoantibodies as a marker of poor prognosis in bullous pemphigoid: a cohort analysis of 94 elderly patients. Br J Dermatol 1997;136:694-8.

26. Joly P, Benichou J, Lok C, et al: Prediction of survival for patients with bullous pemphigoid: a prospective study. Arch Dermatol 2005;141:691-8.

27. Bernard P, Reguiai Z, Tancrède-Bohin E, et al: Risk factors for relapse in patients with bullous pemphigoid in clinical remission: a multicenter, prospective, cohort study. Arch Dermatol 2009;145:537-42. 